\section{Impact of age and duration on sight-threatening retinopathy in South Asians and Caucasians attending a diabetic clinic}

\begin{abstract}
Aims To examine diabetic retinopathy in Asians and Caucasians attending a hospital diabetic clinic and to evaluate the impact of the significant risk factors on the probability of sight-threatening retinopathy.
\end{abstract}

Methods A total of 500 diabetic patients (268

Asians, 232 Caucasians) who attended a diabetic clinic within a defined time period were examined for severity of diabetic retinopathy. The existence of sight-threatening retinopathy (STR) was compared in the two groups. Significant risk factors such as age, duration and hypertension were analysed against the probability of STR in each of the two races.

Results Asians demonstrated significantly higher rates of STR. Univariate analysis showed age, duration, race, gender, and insulin-requiring status to be significantly associated with STR. Multivariate logistic regression showed a significant association of STR with race, age and duration of diabetes, with no significant interaction effects between variables. The logistic regression model predicted STR in Asians to be matched to that in Caucasians by a 12.5-year difference factor; that is, Caucasians were older by $\mathbf{1 2 . 5}$ years or had a 12.5-year longer duration than Asians for the same level of STR.

Conclusions After adjusting for age and duration of diabetes, the probability of STR in Asian diabetic patients attending the diabetic clinics in Bradford is significantly higher than that in Caucasians (odds ratio $=3.184, P<0.05$ ). The impact of age and duration was significantly higher in patients of South Asian origin compared to Caucasians.
S Pardhan ${ }^{1}$, J Gilchrist ${ }^{2}$ and I Mahomed ${ }^{3}$

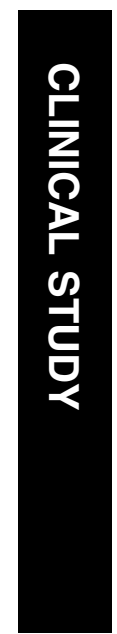

Eye (2004) 18, 233-240. doi:10.1038/sj.eye.6700629

Keywords: diabetic retinopathy; Asians;

Caucasians; age; duration

\section{Introduction}

Roughly $2-4 \%$ of the UK adult population suffer from diabetes, and about $5 \%$ of total health care expenditure is spent on the care of people with diabetes. ${ }^{1}$ Studies in various parts of the world $^{2-5}$ including the $\mathrm{UK}^{6-10}$ report a higher prevalence of diabetes in Asians of Indian origin (originating from the Indian subcontinent) than in other races. The order of increase in prevalence of diabetes in Asians could be as high as four times that of people of European (Caucasian) origin. ${ }^{7}$ A gender effect has also been reported in that Asian males up to the age of 60 years show a higher prevalence of diabetes than females. ${ }^{11}$ In older patients, the prevalence rates in males and females are similar, possibly as a result of an increase in mortality in Asian men from cardiovascular disease. ${ }^{12}$

Not surprisingly, comparison of diabetic complications between Asians and Caucasians generally mirrors the findings on prevalence of the disease. Data for England and Wales ${ }^{13}$ show that mortality from diabetes in South Asians is more than three times the national rate, with diabetic nephropathy and end-stage renal failure being more common. ${ }^{14}$ A study in Ealing (London) reported that despite a shorter duration and younger age, Asian patients had similar symptomatic ischaemic heart disease, hypertension, retinopathy, and lens opacities as in Caucasians, ${ }^{15}$ while in Leicester it was found that, although Asians were significantly older at
${ }^{1}$ Department of Optometry Anglia P University

Cambridge, UK

${ }^{2}$ Department of Optometry University of Bradford Bradford, UK

${ }^{3}$ Bradford Royal Infirmary Bradford, UK

Correspondence:

$S$ Pardhan

Department of Optometry

Anglia P University

Cambridge CBI IPT, UK

Tel: +441223

3632712257

Fax: + 441223417712

apu.ac.uk

Received: 30 December 2002

Accepted in revised form: 24 April 2003

Presented at ARVO 2001

Proprietary interest: None
E-mail: s.pardhan@ 
diagnosis and had shorter diabetes duration than Caucasians, they showed similar prevalence of ischaemic heart disease, lower peripheral vascular disease and retinopathy, and higher prevalence of renal disease. ${ }^{16}$

Although many studies have reported on the disease itself for Asians and Caucasians, comparative studies on the prevalence and severity of retinopathy between the two racial groups in the UK are relatively few and show varied evidence. Some report higher prevalence of retinopathy in Asians than in Caucasians, ${ }^{17}$ some find no difference ${ }^{15}$ while others find a lower prevalence in Asians. ${ }^{16}$ It is difficult to compare these studies directly, as various methodological reasons account for the differences including exclusion criteria, point of examination (at diagnosis only), and the type of data collected (presence/absence of retinopathy).

A house-to-house study investigating ocular health of 200 South Asians aged over 50 years in Bradford, UK ${ }^{18}$ showed that a large percentage $(16 \%)$ had diabetes and that nearly half of these reported that diabetes has affected their eyes. This figure is higher than reported elsewhere. Another study, also carried out in Bradford, reported that a significantly higher proportion of lowvision registrations in South Asians were due to diabetic retinopathy compared to Caucasians. ${ }^{19}$ The aim of the present study is to investigate more fully the severity of diabetic retinopathy in a sample of South Asian diabetic patients attending a diabetic clinic in Bradford, and to compare them with a similar sample of Caucasian patients from the same area. Clinical features, such as age, duration, etc, were also examined. The methodology used was similar to that used in previous comparative studies. ${ }^{16,20}$

\section{Materials and methods}

\section{Data collection}

All eligible diabetic patients who attended an outpatient diabetic clinic between March 1996 and December 1997 were invited to participate in the study. Patients were included if they were over 40 years of age, were diagnosed as diabetic, and had not been treated for any other eye diseases such as glaucoma. The patients attended the diabetic clinic for their annual check. A total of 500 patients took part, of whom 232 were Caucasians born in the UK and 268 were of South Asian origin. A total of $7 \%$ (Asian: $4 \%$, Caucasian: $3 \%$ ) of eligible patients who were invited refused to participate. All Asians were born abroad in Pakistan, India or Bangladesh and had settled in Bradford (Table 1). Informed consent was obtained from each patient after explanation of the study.

The grading of retinopathy was carried out by an experienced ophthalmologist who specialises in diabetes, who has over 20 years experience in the assessment and management of retinopathy, and is also a tutor in grading of retinopathy for Bradford's Diabetic Monitoring Scheme. Direct and slit-lamp indirect ophthalmological examinations were carried out after pupil dilation. Validation of the retinopathy was confirmed by means of retinal photographs and fluorescein angiography on all subjects. Retinopathy was classified according to the grade of retinopathy and was similar to that used by Nicholl et al. ${ }^{15}$ Patients were assigned to four groups according to their retinopathy status: no retinopathy, background retinopathy (which included microaneurysms, dot haemorrhages, or hard exudates alone), preproliferative changes (IRMA, cotton wool spots in addition to background retinopathy) and maculopathy or proliferative changes (new vessels, fibrous traction bands, etc). For analysis, no retinopathy and background retinopathy were classified as non-sight threateningretinopathy (NSTR). Preproliferative changes and maculopathy or proliferative changes were classified as sight-threatening-retinopathy (STR). Patients who had any pan-retinal photocoagulation were included in the STR category. In each case, the retinopathy status recorded for the purposes was that of the poorer eye. There were no patients whose retinopathy could not be

Table 1 Clinical and demographic details of the subjects

\begin{tabular}{|c|c|c|}
\hline & Caucasians: $\mathrm{n}=232$ & Asians: $\mathrm{n}=268$ \\
\hline Gender & M: 105 (45\%); F: 127 (55\%) & M: $140(52 \%) ; \mathrm{F}: 128(48 \%)$ \\
\hline Mean age & $\begin{array}{l}\text { Median: } 61.30 \text { years } \\
\text { (range: } 41-80 \text { years) }\end{array}$ & $\begin{array}{l}\text { Median: } 61.30 \text { years } \\
\text { (range: } 58-87 \text { years) }\end{array}$ \\
\hline Mean duration & $\begin{array}{l}\text { Median: } 8.00 \text { years } \\
\text { (range: } 0-35 \text { years) }\end{array}$ & $\begin{array}{l}\text { Median: } 9.73 \text { years } \\
\text { (range: } 0-29 \text { years) }\end{array}$ \\
\hline Country of birth & UK $(46.4 \%)$ & $\begin{array}{l}\text { India }(8.2 \%) \text {, Pakistan }(38.4 \%) \text {, } \\
\text { Bangladesh }(4.6 \%) \text {, other }(2.4 \%)\end{array}$ \\
\hline Age at diagnosis & $\begin{array}{l}\text { Median: } 50.81 \text { years } \\
\text { (range: } 23-80 \text { years) }\end{array}$ & $\begin{array}{l}\text { Median: } 50.20 \text { years } \\
\text { (range: } 19-78 \text { years) }\end{array}$ \\
\hline No. diagnosed before the age of 30 years & 3 subjects & 6 subjects \\
\hline Insulin requiring & $134(51 \%)$ & $162(60 \%)$ \\
\hline
\end{tabular}


Table 2 Univariate analysis showing significant associations between STR and age, duration, race, gender, insulin-requiring status, and hypertensive

\begin{tabular}{|c|c|c|c|c|c|c|c|}
\hline \multirow[t]{2}{*}{ Variable } & \multirow[t]{2}{*}{ Type } & \multirow[t]{2}{*}{ Units/categories } & \multirow[t]{2}{*}{ Measure } & \multicolumn{2}{|c|}{ STR } & \multirow[t]{2}{*}{ Statistic } & \multirow[t]{2}{*}{ P-value } \\
\hline & & & & Present & Absent & & \\
\hline \multirow[t]{3}{*}{ Age } & \multirow[t]{3}{*}{ Continuous } & \multirow[t]{3}{*}{ years } & Mean & 66.60 & 56.37 & \multirow[t]{3}{*}{$t$-test } & \multirow[t]{3}{*}{$4.67 \mathrm{E}-25$} \\
\hline & & & SD & 9.99 & 10.24 & & \\
\hline & & & $n$ & 188 & 312 & & \\
\hline \multirow[t]{3}{*}{ Duration } & \multirow[t]{3}{*}{ Continuous } & \multirow[t]{3}{*}{ years } & Mean & 12.91 & 7.57 & \multirow[t]{3}{*}{$t$-test } & \multirow[t]{3}{*}{$6.23 \mathrm{E}-17$} \\
\hline & & & SD & 8.06 & 5.69 & & \\
\hline & & & $n$ & 188 & 312 & & \\
\hline \multirow[t]{2}{*}{ Race } & \multirow[t]{2}{*}{ Categorical } & 1-Asian & Freq & 125 & 143 & \multirow[t]{2}{*}{$\chi^{2}$} & \multirow[t]{2}{*}{0.00001} \\
\hline & & 0 - Caucasian & & 63 & 169 & & \\
\hline \multirow[t]{2}{*}{ Gender } & \multirow[t]{2}{*}{ Categorical } & 1 -Male & Freq & 102 & 143 & \multirow[t]{2}{*}{$\chi^{2}$} & \multirow[t]{2}{*}{0.06804} \\
\hline & & 0 -Female & & 86 & 169 & & \\
\hline \multirow[t]{2}{*}{ Insulin requiring } & \multirow[t]{2}{*}{ Categorical } & 1 -Yes & Freq & 121 & 175 & \multirow[t]{2}{*}{$\chi^{2}$} & \multirow[t]{2}{*}{0.06831} \\
\hline & & $0-\mathrm{No}$ & & 67 & 137 & & \\
\hline \multirow[t]{3}{*}{$\mathrm{HbA1}$} & \multirow[t]{3}{*}{ Continuous } & \multirow[t]{3}{*}{$\%$} & Mean & 9.13 & 9.21 & \multirow[t]{3}{*}{$t$-test } & \multirow[t]{3}{*}{0.143} \\
\hline & & & SD & 2.1 & 2.3 & & \\
\hline & & & $n$ & 188 & 312 & & \\
\hline \multirow[t]{2}{*}{ Hypertensive } & \multirow[t]{2}{*}{ Categorical } & $1-$ Yes & Freq & 64 & 113 & $\chi^{2}$ & 0.62222 \\
\hline & & $0-\mathrm{No}$ & & 124 & 119 & & \\
\hline
\end{tabular}

Note: Data for AGE and DURATION are not normally distributed (Kolmogorov-Smirnov: AGE $d=0.056, P<0.10 ;$ DURATION $d=0.218, P<0.01$ ). Significance tests were therefore confirmed using Mann-Whitney $U$ (rank sum) statistics in place of $t$ statistics and gave values as follows: Age $P=6.76 \mathrm{E}-23$; DURATION $P=3.48 \mathrm{E}-14$. Means, SD, and $t$ statistics are reported in the table for ease of interpretation.

graded. Grading of retinopathy was carried out on the patient and therefore it was not strictly a masked study.

Clinical information, including age of the patient, duration of diabetes, sex and insulin-requiring status, and the last HbA1 levels, was obtained from clinical records. Age was defined as the age at the time of examination. The duration of diabetes was the time period between the age at diagnosis and the age at the time of examination. It is appreciated that the duration was calculated from time of diagnosis and therefore may not be an accurate record as patients may have had diabetes for quite some time before they were diagnosed. Other data such as presence of hypertension, advice to reduce cholesterol levels and country of birth were obtained by means of a questionnaire that formed part of a larger study investigating lifestyle issues.

\section{Statistical analysis}

We used SPSS v10 for all analysis. Patients with STR were compared to those with NSTR across all other variables to establish whether any factors appeared significantly associated with retinopathy status. Univariate analysis, $t$-tests, and $\chi^{2}$ tests were employed to compare continuous and categorical data.

\section{Binary logistic regression: model fitting}

Binary logistic regression was employed with the aim of modelling the probability of a patient having STR, given certain characteristics of race, age, duration of diabetes, etc. The dependent variable $(y)$ is STR and the independent $(x)$ variables to be included were ascertained by univariate analysis. Since in epidemiological studies it is possible to set a generous significance criterion (eg $P<0.10),{ }^{21-22}$ those variables significantly associated with STR were included in the multivariate model.

Forward stepwise analysis (backward elimination) determined significant variables. The variables were added to the model according to their univariate significance and evaluated to see whether addition of each variable gave a significant improvement in the fit of the model to the data.

The linearity of each continuous variable on the log odds scale was confirmed by dividing each of the variables of age and duration into 10 decile groups $(j=1, \ldots, 10)$. This enabled approximately equal numbers of individuals to fall into each group. The proportions $p_{j}$ of patients with STR were then calculated for each group (j) and the logit of these values, that is, $\ln \left\lfloor p_{j} / 1-p_{j}\right\rfloor$, were plotted against the mid-points of corresponding age quartiles. The coefficients of determination $\left(r^{2}\right)$ of 0.762 and 0.885 for age and duration, respectively, confirmed linearity of the logits.

\section{Results}

Of the total patients examined, $62 \%$ had NSTR $(40 \%$ had no retinopathy, $22 \%$ had background retinopathy) and $38 \%$ had STR (29\% had pre-proliferative and 
Table 3 Multivariate logistic regression model predicting STR from race, age and duration of diabetes

\begin{tabular}{lrrrr}
\hline Variable & $\beta$ & $S E(\beta)$ & $W=B / S E(B)$ & Odds ratio (95\% CI) \\
\hline Constant & -7.6634 & 0.7787 & -9.8411 & \\
Age & 0.0906 & 0.0114 & 7.9575 & $1.083(1.071,1.120)$ \\
Duration & 0.0935 & 0.0166 & 5.6326 & $1.098(1.063,1.134)$ \\
Race & 1.1582 & 0.2310 & 5.0140 & $3.184(2.023,5.013)$
\end{tabular}

Goodness of fit: deviance ( $-2 \log$ likelihood). Intercept-only $D_{0}=662.072$, model $D \mathrm{M}, 497.428 . \chi^{2}$ for covariates $D_{0}-D_{\mathrm{M}}=G_{\mathrm{M}}=164.644, P$-value $=1.82 \mathrm{E}-35$. Hosmer and Lemeshow test $\chi^{2}=6.419, P$-value $=0.6005, \mathrm{df}=8 . \chi^{2}$ and Hosmer and Lemeshow goodness of fit indicate an acceptable goodness of fit of the logistic regression model for predicting the probability of STR from age, duration of diabetes and race.

maculopathy and $9 \%$ had proliferative retinopathy). In order to ascertain whether there were any drifts in the diagnosis of retinopathy, the number of patients diagnosed with STR was determined after each consecutive 100 patients and was found to be similar for each of the five groups.

Univariate analysis is shown in Table 2. Age, duration of diabetes and race are shown to be very significantly associated with presence of STR $(P<0.001)$. Gender and insulin-requiring status show slightly lower significance levels $(0.1>P>0.05)$. Since in epidemiological studies it is possible to set a generous significance criterion (e.g. $P<0.10),{ }^{21-22}$ those variables significantly associated with STR were included in the multivariate model.

Age, duration, race, gender and insulin-requiring status were included in the multivariate model. The model allowed the retention of only three variables with the most significant effects; age, duration of diabetes and race. A multivariate logistic regression model was fitted using these three variables and the fit of the model was evaluated.

Table 3 reports the fit of the multivariate logistic regression model predicting STR from age, duration, and race. The table lists the regression coefficients $(\beta)$ with their standard errors SE $(\beta)$. The ratio of each coefficient divided by its standard error, $W=\beta / \mathrm{SE}(\beta)$, provides a measure of the statistical significance of the coefficient. In large samples, $W$ follows a standard normal distribution, ${ }^{21-22}$ so values of $W$ whose magnitude exceeds 3.0 will be highly significant. This is shown for age, duration and race. Table 3 also gives the odds ratios for the regression coefficient $(\mathrm{OR}=\exp (\beta))$.

The method used to examine the goodness-of-fit of the model is detailed in the Appendix. Table 3 demonstrates the odds for an Asian diabetic patient with STR to be 3.184 times higher than a Caucasian patient of the same age and duration of disease. Figures 1 and 2 show the proportion of STR for Asians and Caucasians for the two variables; age and duration of the disease, respectively. Figures $3 a$ and $b$ show the prediction of the model for various age groups across duration for Asians and Caucasians, respectively. The predicted functions for

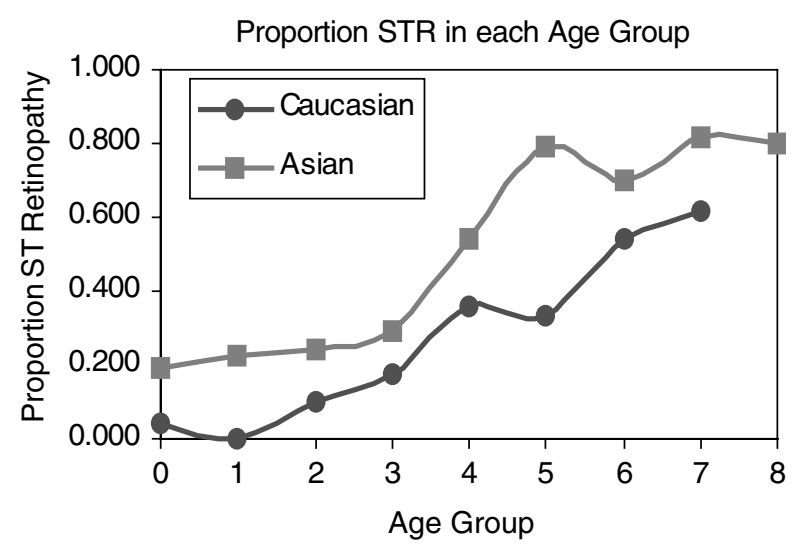

Figure 1 Proportion of STR for Asians and Caucasians at different levels of Age at diagnosis groups. The different age groups are $0=>45$ years, $1=45-<49$ years, $2=50-<54$ years, $3=55-<59$ years, $4=60-<64$ years, $5=65-<69$ years, $6=70-$ $<74$ years, $7=75-<79$ years, $8->80$ years.

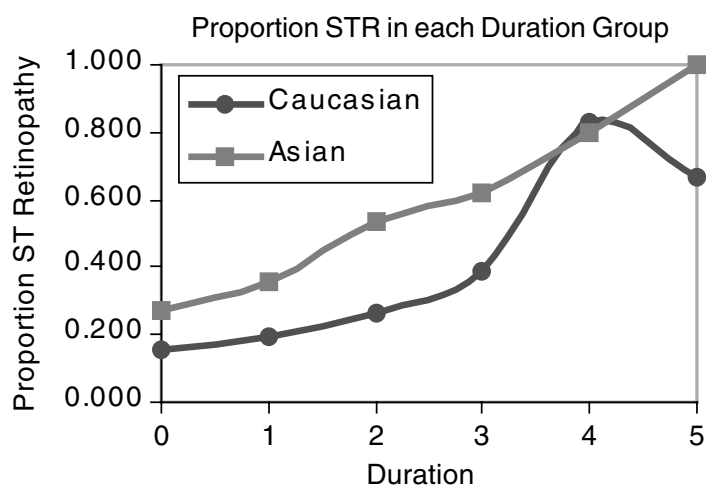

Figure 2 Proportion of STR for Asians and Caucasians at different levels of duration. The different duration groups are: $0=<5$ years, $1=5-<10$ years, $2: 10-<15$ years, $3=15-<20$ years, $4=20-<25$ years, and $5 \geqslant 25$ years.

Asians and Caucasians superimpose on each other when the Caucasian data have been shifted along the $\mathrm{x}$-axis by 12.5 years for age (Figure 4a) and for duration (Figure $4 \mathrm{~b})$, suggesting that Caucasians are approximately 12.5 years older and/or have had diabetes for 12.5 years more to have the same STR levels compared to Asians. 


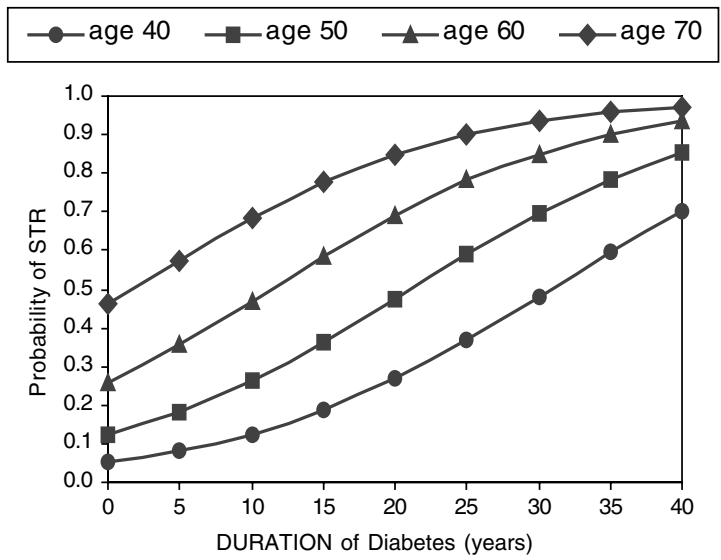

b STR Prediction (CAUCASIAN Patients)

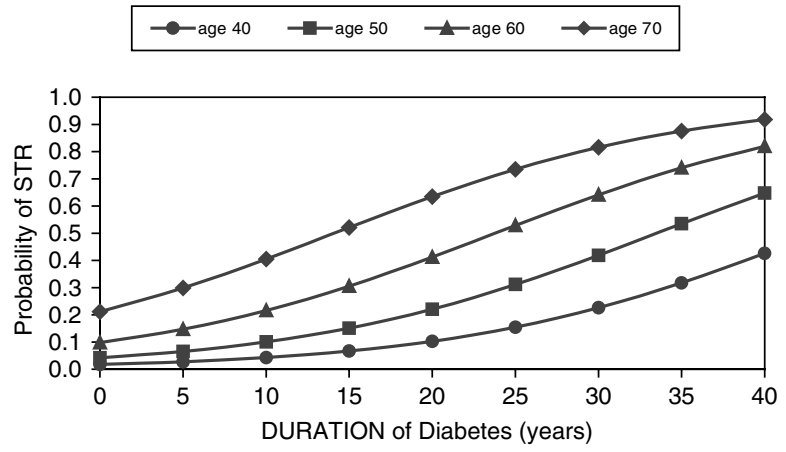

Figure 3 Predictions for the probability of STR for different age groups and duration: (a) Asians and (b) Caucasians.

\section{Discussion}

The results of the study demonstrate the high probability of STR in South Asians attending the same diabetic clinic as Caucasians within a specified period of time. The prevalence of STR may be higher than expected. This is because of the definition of STR adopted in this study to include preproliferative changes, which may, in some cases, include mild preproliferative changes such as one or two cotton wool spots. Although this may not be sight threatening from a clinical expert's point of view, to allow an accepted research standard to be maintained across the whole study, retinopathy was classified according to the method used by Nicholl et al. ${ }^{15}$ Moreover, the study highlights the relative difference between Asians and Caucasians, as the same definitions apply to both groups.

It is important that these data are not seen strictly as representing all Caucasians and Asian diabetics in their communities as the study is subject to some limitations: results were obtained from patients attending a diabetic clinic who may not necessarily represent the a

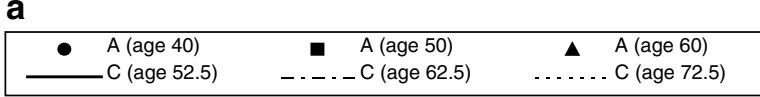

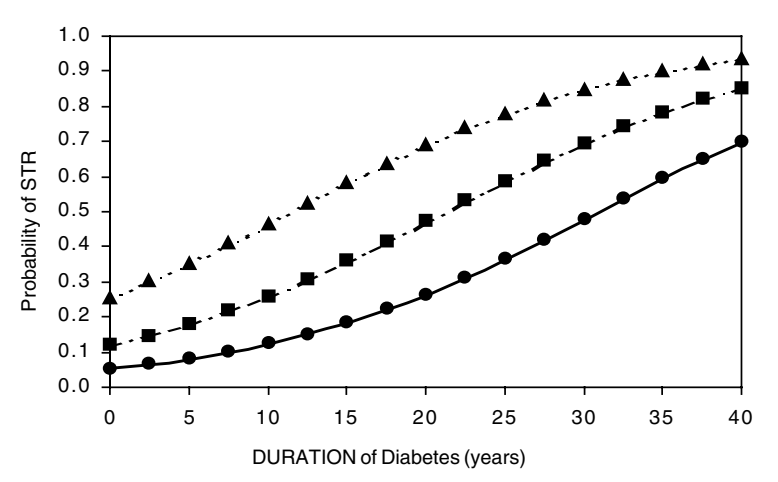

b
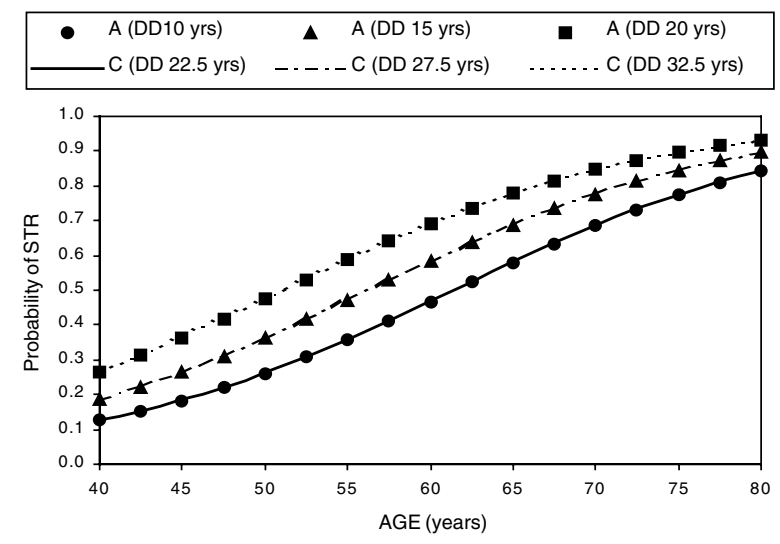

Figure 4 Predictions for the probability of STR in Asians compared to Caucasians whose functions have been shifted by (a) 12.5 years for age and (b) 12.5 longer for duration of diabetes.

profile of the whole Asian or Caucasian community, as there would be patients who do not attend clinics for a number of reasons including cultural, social, economical, etc. These patients not attending diabetic clinics may indeed have worse retinopathy and the profile may well be worse than shown by our data here. Only a large, community-based epidemiological study would reveal this. The study was not masked, which could lead to bias. However, as other data were also required, it was difficult to conduct a masked study. It is appreciated that an assessment of photographic records might have been more accurate and would have allowed the validity of the data to be checked. As only one experienced ophthalmologist graded the photographs, this would have eliminated any inter-observer variability. It is also possible that a delayed diagnosis in the Asian group compared to the Caucasian group may have occurred. Unfortunately, we do not have data on how long the patients had been permanently resident in the country. However, significant differences in STR are also shown with 
our data between the two races for the same age group.

Various factors are known to be associated with the development and progression of diabetic retinopathy. We confirm significant associations for some of these factors including age, duration, gender and treatment of STR. The higher probability of STR despite the lack of significant difference between last $\mathrm{HbA} 1$ levels in the two racial groups demonstrates that, irrespective of the causes, differences in retinopathy exist between the two groups attending the same clinic. It was interesting that no significant effect of $\mathrm{HbA1}$ level was shown with the presence of STR retinopathy. This may be because the last HBA1 level was used and an initial recorded or even the median HbA1 level may indeed have shown a significant effect with the presence of STR. However, since some patients had attended many clinics over a number of years while others had only attended a clinic or two, it was considered more appropriate to record the last HBA1 level. Another interesting observation is the lack of association between retinopathy and hypertension even though the association between the two is well known. ${ }^{23,24}$ One possible reason for this discrepancy is that hypertension was not measured in this study but was judged to be present or absent according to the patient's self reports. This may have led to misreporting or misinformation by the patient.

The significant observed effect of race found in this study has not been reported previously. The UK Prospective Diabetes Study group ${ }^{25}$ reported no differences in retinopathy levels between Asians and Caucasians at diagnosis. However, their Asian subjects were significantly younger than Caucasians. Since age is a significant risk factor for diabetic retinopathy, it would not be inappropriate to assume that these younger Asian subjects may well go on to demonstrate higher levels of retinopathy during their illness when age-matched to Caucasians. No previous study has carried out a comprehensive analysis of STR in Asians and Caucasians. A study by Samanta et al ${ }^{16}$ showed, interestingly, a lower prevalence of retinopathy in Asians compared to Caucasians, despite the Asian subjects having significantly higher HbA1 levels, body mass index, and being older. The difference in diabetic retinopathy existed even when duration, which was nearly twice that in Asians, was controlled.

Various possible factors may contribute towards the observed higher STR in Asians. It is well known that Asians have a higher prevalence of diabetes. Various hypotheses for this increased prevalence have been suggested in a review by Greenhalgh. ${ }^{26}$ Although a vast body of literature exists to explain the known high prevalence of diabetes in Asians, there are surprisingly very few detailed studies on risk factors for diabetic complications between ethnic groups. ${ }^{15,27}$ Some of these factors affecting the prevalence of the disease may also explain the increased STR in Asians.

Diabetes increases the impact of major risk factors for cardiovascular disease ${ }^{28}$ and Asians are more likely to develop premature coronary heart disease. ${ }^{29}$ Asians demonstrate lower levels of high-density lipoprotein levels and higher levels of low-density lipoprotein and higher triglyceride levels, ${ }^{30}$ which have been associated with retinopathy. ${ }^{31}$ In addition, end-stage renal failure is higher in South Asians, ${ }^{32,33}$ which is also a risk factor for diabetic retinopathy. ${ }^{34}$ Asians tend to have higher levels of microalbuminuria, ${ }^{35}$ which has been associated with diabetic retinopathy. ${ }^{36}$ Higher total plasma insulin concentration has been reported, ${ }^{37-39}$ which seems to be genetically predetermined ${ }^{40}$ and which is a risk factor for retinopathy. Other reasons may include increased vitamin $\mathrm{D}$ deficiency in Asians ${ }^{41}$ which has been shown to affect diabetic retinopathy, ${ }^{42}$ earlier changes required in treatment in Asians ${ }^{37}$ which is considered a risk factor, ${ }^{43}$ and heath care access which will invariably affect control, diagnosis, and progression and eventually make an impact on diabetic retinopathy. Precisely how these different risk factors influence diabetic retinopathy in the two races is largely undetermined. This study highlights important areas for further research into diabetic retinopathy in Asians and Caucasians.

\section{Acknowledgements}

We thank Dr Mark Hurst for his invaluable advice and input during the earlier stages of the study and Mr Darcy Brown for collecting the data on the questionnaire.

\section{References}

1 British Diabetic Association. Counting the Cost: The Real Impact Of Non-Insulin Dependent Diabetes. King's Fund: London, 1996.

2 Poon-King T, Henry MV, Rampersand F. Prevalence and natural history of diabetes in Trinidad. Lancet 1968; I: 155-160.

3 Jackson WPU. Epidemiology of diabetes in South Africa. In: Advances in Metabolic Disorders, Vol 9. New York, Academic Press, Miller M, Bennett PH (eds). 1978, pp 111-146.

4 Zimmet P, Taylor R, Ram P, King H, Sloman G, Rapier LR et al. Prevalence of diabetes and impaired glucose tolerance in the biracial (Melanesian and Indian) population of Fiji: a rural urban comparison. Am J Epidemiol 1983; 118: 673-688.

5 McKeigue PM, Miller GJ, Marmot MG. Coronary heart disease in South Asians overseas - a review. J Clin Epidemiol 1989; 42: 597-609.

6 McKeigue P, Sevak L. Coronary Heart Disease in South Asian Communities: A Manual for Health Promotion. Health Education Authority: London, 1994.

7 Mather HM, Keen H. The Southall diabetes survey: Prevalence of known diabetes in Asian and Europeans. BMJ 1985; 291: 1081-1084. 
8 Samanta A, Burden AC, Fent B. Comparative prevalence of non-insulin dependent diabetes mellitus in Asian and White Caucasian adults. Diabetes Res Clin Pract 1987; 4: $1-6$.

9 Simmonds D, Williams DRR, Powell MJ. Prevalence of diabetes in a predominantly Asian community: preliminary findings of the Coventry diabetes study. BMJ 1989; 289: 18-21.

10 Dodson PM, Kritzinger EE, Clough CG. Diabetes mellitus and retinal vein occlusion in patients of Asian, West Indian and White European origin. Eye 1992; 6: 66-68.

11 Sharp CL, Butterfield WJH, Keen H. Diabetes survey in Bedford 1962. Proc R Soc Med 1964; 57: 193-202.

12 Balarajan R, Bulusu L, Adelstein AM, Shuckla V. Pattern of mortality amongst migrants to England and Wales from the Indian subcontinent. BMJ 1984; 289: 1185-1187.

13 Raleigh VS. Diabetes and hypertension in Britain's ethnic minorities: implications for the future of renal services. BMJ 1997; 314: 209-213.

14 Burden AC, McNally PG, Feehally J, Walls J. Increased incidence of end-stage renal failure secondary to diabetes mellitus in Asian ethnic groups in the United Kingdom. Diabetes Med 1992; 9: 641-645.

15 Nicholl CG, Levy JC, Mohan V, Rao PV, Mather HM. Asian diabetes in Britain: a clinical profile. Diabetes Med 1986; 3: 257-260.

16 Samanta A, Burden AC, Jagger C. A comparison of the clinical features and vascular complications of diabetes between migrant Asians and Caucasians in Leicester. Diabetes Res Clin Prac 1991; 14: 205-214.

17 Das BN, Thompson JR, Patel R, Rosenthal AR. The prevalence of eye disease in Leicester: a comparison of adults of Asian and European descent. J R Soc Med 1994; 87: 219-222.

18 Pardhan S, Mughal N, Mahomed I. Self-reported eye disease in elderly South Asian subjects from an inner city cluster in Bradford: a small-scale study to investigate knowledge and awareness of ocular disease. Eye 2000; 14: 620-624.

19 Pardhan S, Mahomed I. The clinical characteristics of Asian and Caucasian patients on Bradford's low vision register. Eye 2002; 16: 572-576.

20 Kalterleibovici O, Vandyk DJ, Leibovici L, Loya N, Erman A, Kremer I et al. Risk factors for development of diabetic nephropathy and retinopathy in Jewish IDDM patients. Diabetes 1991; 40: 204-210.

21 Hosmer DW, Lemeshow S. Applied Logistic Regression. Wiley: New York, 1989.

22 Menard S. Applied Logistic Regression Analysis. (Sage University Paper series on Quantitative Applications in the Social Sciences, series no. 07-106). Sage: Thousand Oaks, CA, 1995.

23 Teuscher A, Schnell H, Wilson PWF. Incidence of diabetic retinopathy and relationship to baseline plasma glucose and blood pressure. Diabetes Care 1988; 11: 246-251.

24 Knowler WC, Bennett PH, Ballintine EJ. Increased incidence of retinopathy in diabetics with elevated blood pressure. New Engl J Med 1980; 302: 645-650.

25 UK Prospective Diabetes Study (UKPDS) group. Differences between Asian, Afro-Caribbean and White Caucasian Type 2 diabetic patients at diagnosis of diabetes (UKPDS 11). Diabetes Med 1994; 11: 670-677.

26 Greenhalgh PM. Diabetes in British South Asians: nature, nurture, and culture. Diabetes Med 1997; 14: 10-18.
27 Roy MS. Diabetic retinopathy in African Americans with type I diabetes. The New Jersey 725 II. Risk factors. Arch Ophthalmol-Chic 2000; 118(1): 105-115.

28 Beeteridge DJ. Diabetic dyslipidaemia. Am J Med 1994; 96(6A): 255-315.

29 McKeigue PM, Ferrie JE, Pierport T, Marmot MG. Association of early onset coronary heart disease in South Asian men with glucose intolerance and hyperinsulinaemia. Circulation 1993; 87: 152-161.

30 Stewart MW, Laker MF, Alberti KGMM. The contribution of lipids to coronary heart disease in diabetes mellitus. J Int Med 1994; 236: 41-46.

31 Guerci B, Meyer L, Sommer S, George JL, Ziegler O, Drouin $\mathrm{P}$ et al. Severity of diabetic retinopathy is linked to lipoprotein (a) in type 1 diabetic patients. Diabetes Metabol 1999; 25: 412-418.

32 Roderick Pj, Jones I, Raleigh VS, McGeown M, Mallick N. Population need for renal replacement therapy in Thames regions. Ethnic dimensions. BMJ 1994; 309: 1111-1114.

33 Burden AC, McNally PG, Feehally J, Walls J. Increased incidence of end-stage renal failure from diabetes mellitus in Asian ethnic groups in the UK. Diabetes Med 1992; 9: 641-645.

34 Aiello LP, Cahill MT, Wong JS. Systemic considerations in the management of diabetic retinopathy. Am J Ophthalmol. 2001; 132: 760-776.

35 Allawi J, Rao PV, Gilbert R, Scott G, Jarrett RJ, Keen H et al. Microabuminuria in non-insulin dependent diabetes: its prevalence in Indian compared to European patients. BMJ 1988; 296: 462-465.

36 Voutilainen- Kaunisto RM, Terasvirta ME, Uasitupa MIJ Niskanen LK.Occurrence and predictors of retinopathy and visual acuity in type II diabetic patients and control subjects 10 year follow up from diagnosis. J Diabetes Complicat 2001; 15: 24-33.

37 Chauduri R, Samanta A, Burden AC. Prevalence of insulin taking diabetes mellitus: differences between (Indian) Asians in the UK. Diabetes Med Suppl 1989; 6: 21 a.

38 Dowse GK, Zimmet PZ, Alberti KGMM, Bringham L, Carlin JB, Tuomilehto J et al. for Mauritius NCD Study Group. Serum insulin distributions and reproducibility of the relationship between 2-hour insulin and plasma glucose levels in Asian Indian, Creole and Chinese Mauritians. Metabolism 1993; 42: 1232-1241.

39 Knight TM, Smith Z, Whittles A, Sahota P, Lockton JA, Hogg $G$ et al. Insulin resistance, diabetes, and risk markers for ischaemic heart disease in Indians, Pakistanis and Bangladeshis: aetiology and possibilities for prevention. Br Heart J 1992; 67: 341-342.

40 Dhawan J, Bray CL, Warburton R, Ghambir DS, Morris J. Insulin resistance, high prevalence of diabetes, and cardiovascular risk in immigrant Asians. Genetic or environmental effect. Br Heart J 1994; 72: 413-421.

41 Williams B. Westernised Asians and cardiovascular disease: nature or nurture? Lancet 1995; 345: 401-402.

42 Taverna MJ, Sola A, Pacher N, Bruzzo F, Guyot C, Slama G et al. Endothelial nitric oxide synthase and vitamin D receptor polymorphisms predict risk for severe diabetic retinopathy. Diabetol Suppl 2001; 44: 145.

43 Henricsson M, Nilsson A, Janzon L, Groop L. The effect of glycaemic control and the introduction of insulin therapy on retinopathy in non-insulin dependent diabetes mellitus. Diabetes Med 1997; 14: 123-131. 


\section{Appendix}

The goodness of fit was examined by means of $\chi^{2}$ for covariates,$^{20}$ also referred to as the Model $\chi^{2}, G_{\mathrm{M}} \cdot{ }^{20}$ This value provides a test of the null hypothesis that the regression coefficients are equal to zero and that inclusion of the independent variables in the model does not improve prediction of the outcome. The large $G_{M}$ value for the present model supports the conclusion that inclusion of the independent variables does improve prediction significantly. Table 3 also reports the Hosmer and Lemeshow ${ }^{21}$ Goodness-of-fit test. This test partitions the data into 10 deciles of risk, and compares observed with expected (model) frequencies of STR in each decile. In this case, a good model fit is confirmed by the small $\chi^{2}$ (large $P$-value) indicating no significant difference between observed and predicted outcomes over the deciles of risk. These statistics together indicate an acceptable goodness-of-fit of the logistic regression model for predicting the probability of STR from AGE, DURATION of diabetes, and RACE (Asian/ Caucasian). 